\title{
ARTÍCULOS ORIGINALES \\ Reacción en cadena de la polimerasa para la detección de toxoplasma gondii en líquido amniótico. Hallazgos en 534 casos estudiados en la fundación gillow \\ Alejandro Giraldo, M.D.,M.P.H ${ }^{1,2}$; Dora Fonseca, Biol ${ }^{1}$; Fred Wilson Lozano, M.D. ${ }^{1,3}$; Jorge E. Orjuela, M.D. ${ }^{4}$, Andrés Gutiérrez, Biol ${ }^{1}$, Ariel Iván Ruiz, M.D. ${ }^{2,5}$
}

Recibido: Nov. 29/2000 - Revisado: Febrero 23/2001 - Aceptado: Mayo 11/2001

\section{RESUMEN}

La infección con toxoplasma gondii durante el embarazo produce compromiso fetal en 9 a $27 \%$ de los casos cuando la gestante se infecta durante el primero o segundo trimestres y 59\% si ocurre durante el tercer trimestre. $\quad$ La infección fetal produce serias consecuencias. El diagnóstico de infección congénita se ha sustentado mediante estudios inmunológicos, los cuales son de difícil interpretación. Esta publicación describe nuestra experiencia con la Reacción en Cadena de la Polimerasa (PCR) en líquido amniótico como predictor de compromiso fetal en gestantes con evidencia inmunológica de infección activa. Entre julio de 1996 y septiembre de 2000 se han evaluado 534 muestras de líquido amniótico, encontrándose una frecuencia de casos positivos del 7.1\%. La frecuencia según edad gestacional fue 6.5\% (12-15 s);16.1\% (16-19 s); 20\% (20-23 s); 21.5\% (24-27s); 17.6\% (28-31 s); $12.7 \%(32-35 \mathrm{~s}) ; \quad 1.7 \%(36-39 \mathrm{~s})$. De los 38 casos positivos 20 son clínicamente normales, uno presenta problemas visuales y otro, leve retardo en el desarrollo psicomotor. De los 16 casos restantes, se presentaron 4 muertes fetales, 11 no han podido ser seguidos y 1 no ha nacido aún. La PCR es una metodología sensible y específica para confirmar infección fetal, y permite tomar medidas terapéuticas aún desde el periodo gestacional mejorando el pronóstico de los infantes infectados.

PALABRAS CLAVES: Toxoplasmosis, Reacción en Cadena de la Polimerasa, PCR, líquido amniótico, infección intrauterina.

\section{SUMMARY}

Infection with Toxoplasma gondii during pregnancy may result in fetal damage this ocurrs in 9 of cases, when the mother acquires the infection during the first trimester. If infection ocurrs during the second trimester the fetal infection is about $27 \%$ and increase up to $59 \%$ when the infection ocurrs in the third trimester. Fetal infection produce serious secuelae. The diagnosis of intrauterine infection based on immunologic studies wich are of difficult interpretation. This article describes our experience with Polymerase Chain Reaction in amniotic fluid as predictor of fetal infection in pregnant women with immunologic evidence of active infection. From July 1996 to September 2000 we have studied 534 amniotic fluid samples and found $7.1 \%$ positive cases. The gestational age were: $12-15 \mathrm{w}$ : $6.5 \%$; 16-19w: 16.1\%; 20-23w: 20\%; 24-27w:21.5\%; 28-31w: 17.6\%; 31-35 w: 12.7\%; and 36-39 w: $1.7 \%$. Of the 38 positive cases, 20 are clinically normal; one child has visual problems and other has mild psychomotor retardation. Of the other 16 cases, there are 4 fetal deaths; 11 lost follow-up and one hasn't born yet. PCR is a sensitive an specific method to confirm fetal infection, in order to initiate intrauterine therapy, with bettetr prognosis.

KEY WORDS: Toxoplasmosis, intrauterine infection, PCR, Amniotic Fluid.

\author{
Fundación Gillow \\ Facultad de Medicina, Universidad Nacional de Colombia \\ Hospital Simón Bolívar- Facultad de Medicina Universidad del Bosque \\ Clínica Reina Sofía \\ Instituto Materno Infantil. Bogotá, Colombia
}




\section{INTRODUCCIÓN}

La toxoplasmosis adquirida durante la gestación puede resultar en infección congénita entre el 9 y $27 \%$ de los casos si se adquiere en el $1^{\circ}$ o $2^{\circ}$ trimestres y $59 \%$ si se adquiere en el tercero. La severidad del compromiso neonatal es mayor entre más temprano se adquiera la infección, pudiendo llegar en algunos casos a producir ceguera, retardo mental o muerte ${ }^{1}$.

La detección temprana y confiable de la infección fetal por T. gondii permite instaurar esquemas terapéuticos que minimicen el impacto de ésta sobre el feto o, en caso que se descarte dicho compromiso, evita el uso de medicamentos con potencial de teratogenicidad $o$ toxicidad materna y fetal ${ }^{2}$.

La detección del parásito en líquido amniótico por medio de técnicas de Biología Molecular como la Reacción en Cadena de la Polimerasa (PCR) se ha convertido en la prueba de elección para la toma de estas decisiones terapéuticas ${ }^{1-3}$.

\section{MATERIALES Y MÉTODOS}

Entre julio de 1996 y septiembre de 2000 se obtuvieron 534 muestras de líquido amniótico de pacientes con evidencia serológica de primoinfección por T. gondii presumiblemente ocurrida durante la gestación. Los criterios utilizados para el diagnóstico fueron:

1- Concentraciones crecientes de $\operatorname{IgG}$ específica antitoxoplasma detectados por ELISA.

2- IgM específica antitoxoplasma positiva detectada por ELISA.
La edad gestacional a la cual se practicó la amniocentesis se describe en la tabla 1.

\section{TÉCNICAS DE LABORATORIO}

Se adaptó la técnica descrita por Hohlfeld et al. ${ }^{3}$, que consiste en una PCR de tipo competitivo, que al utilizar un control interno de amplificación (fago m13mp18), evita posibles falsos negativos. El blanco de amplificación es el gen repetido altamente conservado, $\mathrm{B} 1 \mathrm{de} \mathrm{T}$. gondii. Como control positivo de amplificación se utilizó DNA extraído de una suspensión de parásitos obtenidos mediante inoculación en ratón. El DNA de las células de líquido amniótico se aisló mediante la técnica de extracción "Salting-Out" (modificada) ${ }^{4}$; para cada reacción de amplificación se utilizaron $500 \mathrm{ng}$ del mismo.

El efecto competitivo entre el control interno y T. gondii se analizó mediante la amplificación de diluciones seriadas combinadas. Los productos de la PCR se analizaron mediante electroforesis en geles de poliacrilamida, en donde la presencia de dos señales de amplificación (143 y $115 \mathrm{pb}$ ) fueron conclusivas de positividad ${ }^{3}$ (Figura 005i01).

\section{RESULTADOS}

La presencia de DNA de T. gondii evidenciada mediante PCR se demostró en 38 muestras de líquido amniótico lo cual corresponde al $7.1 \%$ de los casos estudiados. La distribución de los casos positivos según edad gestacional se describe en la tabla 2.

La mayoría de las pacientes a quienes se les demostró PCR (+) para T. gondii en líquido amniótico

Tabla 1.

Número de amniocentesis realizadas según edad gestacional.

\begin{tabular}{|lccc|}
\hline Edad gestacional & Número & $\begin{array}{c}\text { \% sobre total de muestras } \\
\text { para la edad gestacional }\end{array}$ & $\begin{array}{c}\text { \% sobre total de } \\
\text { muestras positivas }\end{array}$ \\
\hline 12-15 semanas & 2 & 5.7 & 5.2 \\
$16-19$ semanas & 7 & 8.1 & 18.4 \\
$20-23$ semanas & 6 & 5.6 & 15.8 \\
$24-27$ semanas & 9 & 7.8 & 23.7 \\
$28-31$ semanas & 8 & 8.5 & 21 \\
32-35 semanas & 5 & 7.3 & 2.6 \\
36-39 semanas & 1 & - & - \\
Sin datos & - & - & 11.1 \\
TOTAL & 38 & & \\
\hline
\end{tabular}


recibieron tratamiento con sulfadiazina, pirimetamina y Ac. folínico, mientras que las que no mostraron PCR (+) continuaron su tratamiento con espiramicina durante todo el embarazo con el fin de evitar el paso transplacentario de $\mathrm{T}$. gondii en el tercer trimestre del embarazo.

De los 38 casos con PCR (+) para T. gondii en líquido amniótico 20 son clínicamente normales, uno presenta problemas visuales y uno leve retardo en el desarrollo psicomotor. De los 16 casos restantes, se presentaron 4 muertes fetales, 11 no han podido ser seguidos y uno no ha nacido aún.

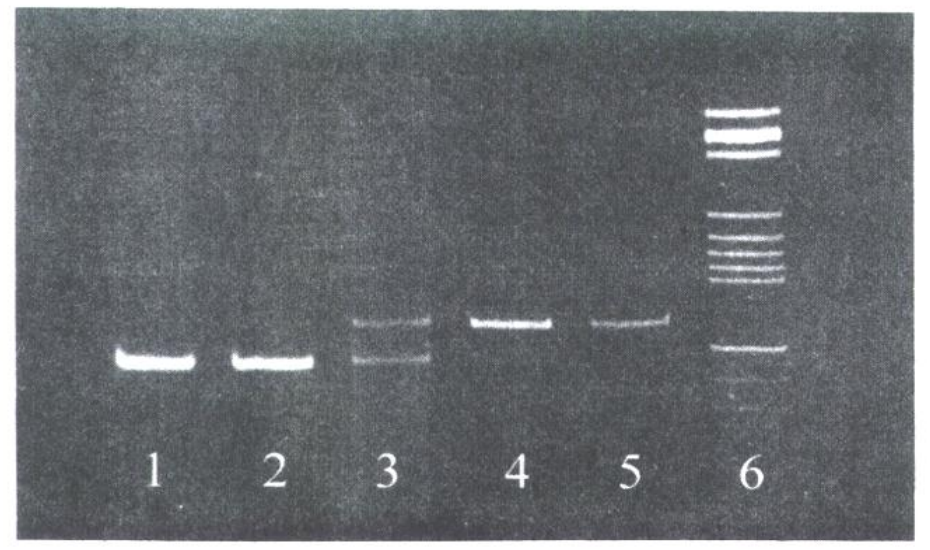

Figura $005 \mathrm{i} 01$

Amplificaciones de T. gondii y fago M13mp 18. Carril 1 y 2: Amplificación de T. gondii. Carril 3: Amplificación de T. gondii y fago M13mp18. Carril 4 y 5 : amplificación de fago M13mp181 Carril 6: marcador molecular PBR322 cortado con Hae III. La visualización se realizó en geles de poliacrilamida al $12 \%$ teñidos con bromuro de etidio. se corrieron una hora y 10 minutos a $160 \mathrm{~V}, 160 \mathrm{~mA}$ y $12 \mathrm{w}$.

\section{DISCUSIÓN}

El presente estudio muestra una frecuencia del $7.1 \%$ de afección fetal en pacientes con infección por toxoplasma durante la gestación lo cual es comparable con trabajos publicados por Hezard y cols5, Forestier y cols ${ }^{6} \mathrm{y}$ Hohlfeld y cols ${ }^{3}$.

La ausencia de muestras positivas en el primer trimestre del embarazo está dada por la edad gestacional en la cual practicamos la amniocentesis ( semana 13 o más), lo cual hace que se acumulen en el $2^{\circ}$ trimestre todos los casos positivos eventualmente ocurridos en el embarazo temprano.

Se adaptó la Reacción en Cadena de la Polimerasa (PCR) para la identificación de T. gondii, mediante el uso de una PCR de tipo competitivo que, al utilizar un control interno de amplificación, evita posibles resultados falsos negativos. Debido a que este control tiene la misma secuencia que el blanco de amplificación, compite con el gen de $\mathrm{T}$. gondii de tal manera que un resultado es considerado negativo solamente si el gen de T. gondii no amplifica, pero la secuencia control si lo hace.

Esta técnica diagnóstica mediante métodos moleculares tiene sensibilidad de $80 \%$ (8) y se logra amplificación de un solo parásito (equivale a 0.048 pg de DNA) ${ }^{7}$. Es importante establecer en el ajuste de la metodología la cantidad de fago adecuada para evitar inhibición de amplificación que lleve a concluir falsa negatividad.

Nuestros resultados indicaron que se logran óptimos resultados de PCR cuando se amplifica 0.415 fg de fago M13 mp18 en la presencia de 15 taquizoitos de T. gondii. El alto poder de detección de esta metodología molecular puede llevar a resultados falsos positivos si no se siguen las recomendaciones

Tabla 2.

Distribucion de casos positivos según edad gestacional

Edad gestacional

12 - 15 semanas

16 - 19 semanas

20 - 23 semanas

24 - 27 semanas

28 - 31 semanas

32 - 35 semanas

36 - 39 semanas

Sin datos

TOTAL
Número

35

86

107

115

94

68

9

20

534
Porcentaje (\%)

6.5
16.1
20
21.5
17.6
12.7
1.7
3.8
100


estrictas que en torno al trabajo en biología molecular han sido establecidas ${ }^{9}$.

\section{BIBLIOGRAFÍA}

1. Remington J., Klein J. Infectious diseases of the fetus and newborn infant. 4th Edition. Philadelphia. W.B. Saunders Company, 1995; 140-267.

2. Wong S.Y., Remington J., Toxoplasmosis in pregnancy. Clin Infec Dis 1994; 18: 853-862.

3. Hohlfeld D., Daffos F. Prenatal diagnosis of congenital toxoplasmosis with a polymerase chain reaction test on amniotic fluid. N Engl Med 1994; 331: 695-699.

4. Miller S., Dykes D. A simple salting out procedure for extracting DNA from human nucleated cells. Nucleid Acids Res 1988; 16: 1215.
5. Herzard N., Marx C., Foudrinier F. Prenatal diagnosis of congenital toxoplasmosis in 261 pregnancies. Pren. Diag 1997; 17: 1047-1054.

6. ForestierF.,HohlfeldP.,SoleY.Prenataldiagnosisofcongenital toxoplasmosis by PCR. Pren Diag 1988; 18: 407-408.

7. MontoyaMT.,GómezJE., Castaño JC. Avances diagnósticos en toxoplasmosis. PCR, nuevos marcadores de infección evolutiva y otras técnicas. Acta Med Col 1996; 21: 127-139.

8. Foulon W., Pinon JM., Stray-Pedersen B et al. Prenatal diagnosis of congenital toxoplasmosis: A multicenter evaluation of differrent diagnostic parameters. Am J Obstet Gynecol 1999; 181: 843-847.

9. Griffin H., Griffin A. PCR technology. 1 st Ed. USA. CRC press; 1994; 249-257. 